\title{
Ueber das specifische Gewicht des Ozongases;
}

\author{
nach Th. Andrews und P. G. Tait*').
}

Andrews und Tait geben in vorläufiger Mitiheilung das Resultat, zu welchem sie bei Versuchen, das spec. Gewicht des Ozongases zu bestimmen, gekommen sind. Der Umstand, dals das Ozongas stets mit einer überwiegend grofsen Menge Sauerstoff gemischt ist (der bei der Electrolyse einer Mischung von 8 Th. Wasser auf $1 \mathrm{Th}$. Schwefelsäurehydral entwickelte Sauerstoff enthielt durchschnittlich ${ }_{3}^{1} \frac{1}{5}$ o seines Gewichts an Ozon, der durch Electrolyse einer Mischung gleicher Volume Wasser und Schwefelsäure entwickelte Sauersloff elwa doppelt so viel Ozon) und daf's das Ozon durch Quecksilber rasch zerstört wird, so dafs es sich nicht über diesem auffangen lälst, liels als einzige Methode, das spec. Gewicht des Ozongases zu bestimmen, die zu, die Volumänderung zu bestimmen, welche ozonhalliger Sauerstoff beim Erhitzen auf $230^{\circ}$ oder darüber erleidet. Hierbei hatte stels Volumvergrölserung statt, die sich, indem die Effecte der Schwankungen in der Temperatur und dem Druck während des Versuchs durch Vergleichung mit den Volumänderungen einer in ein ähnliches Gefäfs eingeschlossenen Menge Gas eliminirt wurden, genau bestimmen liefs. Die bei den Versuchen benutzlen Gefäfse fafsten 200 bis $600 \mathrm{CC}$. und endigten in etwa 2 Millimeter weite Gasröhren, die Uförmig gebogen und mit Schwefelsäure abgesperrt waren; die Menge des darin enthaltenen Ozons wurde abgeleilet aus dem Ozongehalt zweier ähnlicher, zu beiden Seiten des ersteren angebrachter Gefäfse.

Als allgemeines Resultat dieser Untersuchungen geben Andrews und Tait an, dafs das spec. Gewicht des Ozons - unter der Voraussetzung, dafs dieses eine allotropische Modification des Sauerstoffs ist - das vierfache von dem des Sauerstoffgases ist.

*) Chem. Gaz. 1857, 319. 